\title{
Articulações entre pesquisa e estágio: a pesquisa-ação enquanto estratégia de formação em educação física
}

\author{
Articulations between research and internship: action- \\ research as a training strategy in physical education
}

\section{Articulaciones entre investigación y prácticas: la investigación-acción como estrategia de formación en educación física}

\author{
(iD) Jamile Dal-Cin \\ Professora da rede pública estadual de ensino, Chapecó, Santa Catarina, Brasil \\ E-mail: jamiledalcin@unochapeco.edu.br \\ iD Neusa Dendena Kleinubing \\ Universidade Comunitária da Região de Chapecó - UNOCHAPECÓ, Chapecó, Santa \\ Catarina, Brasil \\ E-mail: neusadk@gmail.com
}

Resumo: Este texto apresenta resultados de uma pesquisa que teve como objetivo analisar as articulações entre estágio e pesquisa-ação nos trabalhos de conclusão de curso de uma licenciatura em EF. Com abordagem qualitativa do tipo documental, foram selecionados 23 trabalhos caracterizados como pesquisa-ação, realizados no período de 2009 a 2019. Na maioria dos trabalhos pesquisados, a pesquisa-ação sustenta a organização da intervenção pedagógica ocorrida nos estágios curriculares obrigatórios, porém apenas 1 apresentou discussões nas quais o estágio e a pesquisa-ação se articulavam a fim de refletir sobre a formação docente. Assim, conclui-se que ainda é necessário avançar nas discussões e nas estratégias de formação docente pela pesquisa, de modo especial, pela pesquisa-ação.

Palavras chave: Pesquisa-ação. Estágio. Formação de professores. Educação Física. 


\begin{abstract}
This text presents results of a research that aimed to analyze the articulations between internship and action-research in the course completion works of a course of Degree in PE. With a qualitative approach of the documentary type, 23 works were characterized as action-research, carried out in the period from 2009 to 2019. In most of the researched works, action-research supports the organization of the pedagogical intervention that took place in the mandatory curricular internships, however, only 1 presented discussions in which the internship and action-research were articulated in order to reflect on teacher education. It is concluded that it is necessary to advance in the discussions and strategies of teacher education through research, especially through action-research.
\end{abstract}

Keywords: Action-research. Internship. Teacher education. Physical education.

Resumen: Este texto presenta los resultados de una investigación que tuvo como objetivo analizar las articulaciones entre pasantía e investigación-acción en los trabajos de conclusión de curso de una licenciatura en EF. Con un enfoque cualitativo de tipo documental, se caracterizaron como investigación-acción 23 trabajos, realizados en el período de 2009 a 2019. En la mayoría de los trabajos, la investigaciónacción apoya la organización de la intervención pedagógica que se realizó en las pasantías curriculares obligatorias. Solo 1 presentó discusiones en las que se articulaban la pasantía y la investigación-acción con el fin de reflexionar sobre la formación docente. Se concluye que es necesario avanzar en las discusiones y estrategias de formación docente, especialmente a través de la investigación-acción.

Palabras-clave: Investigación-acción. Pasantía. Formación de profesores. Educación Física.

Submetido em: 29-09-2020

Aceito em: 15-01-2021 
Articulações entre pesquisa e estágio: a pesquisa-ação enquanto estratégia de formação... Jamile Dal-Cin • Neusa Dendena Kleinubing

\section{Considerações Iniciais}

A formação de professores tem se revelado uma problemática complexa que envolve diferentes atores e cenários, além de requerer da instituição formadora ações no sentido de viabilizar uma formação que, através de ações relacionadas ao ensino, pesquisa e extensão, possam oportunizar ao estudante da licenciatura compreender a atualidade da educação brasileira.

Uma das dimensões do processo de formação que efetiva a aproximação do estudante ao contexto da futura atuação profissional é o Estágio Curricular Obrigatório (ECO). Entendemos que o ECO deve estar intrinsecamente articulado à prática e ao trabalho acadêmico, bem como deve ser entendido na perspectiva da produção do conhecimento em um processo no qual saberes oriundos dos outros componentes curriculares devem ser refletidos e aprofundados a partir das experiências travadas no contexto da escola.

A prática da pesquisa no processo de formação de professores pode provocar uma mudança na percepção do próprio sujeito, da sua realidade e da futura atuação docente. É um processo que privilegia a produção de conhecimentos e, quando pensada na perspectiva de articulação com o ensino - neste caso no momento do estágio -, se potencializa na medida em que é a prática pedagógica do próprio estudante que está à luz do olhar curioso e investigativo. Nisso, Rezer (2014) propõe pensar o estágio como um laboratório pedagógico no qual é possível identificar as potencialidades e fragilidades da formação a partir do "caminho de volta", ou seja, além de ser espaço privilegiado para o estudante aprender a "ser professor", o estágio também contribui para que o curso avalie a formação proposta, naquilo que há de positivo e no que precisa avançar e, nesse processo, a pesquisa pode constituir-se como uma grande aliada.

Nessa direção, este artigo tem como objetivo analisar em que medida a pesquisa-ação enquanto estratégia de intervenção nos 
Articulações entre pesquisa e estágio: a pesquisa-ação enquanto estratégia de formação... Jamile Dal-Cin • Neusa Dendena Kleinubing

estágios contribui para a formação de professores de Educação Física, buscando construir subsídios para qualificar o processo de formação inicial do licenciado a partir da investigação dos trabaIhos de conclusão de curso que se articulam ao estágio (ensino) e se caracterizam como pesquisa-ação. Acreditamos que identificar a quantidade dessas pesquisas, bem como seus resultados, pode apresentar indicativos para a reformulação do projeto pedagógico do curso no sentido de que, talvez, essa opção de pesquisa possa ser instituída regularmente como trabalho de conclusão de curso, articulando o ensino e a pesquisa a fim de contribuir com uma formação de professores que se percebam como produtores de conhecimento. Na sequência, apresentamos o percurso metodológico realizado, os achados desta investigação e, por fim, a síntese conclusiva.

\section{Percurso metodológico}

A presente investigação se caracterizou pela abordagem qualitativa (MINAYO, 2008), do tipo documental. A opção pela pesquisa documental se justifica pelo fato de possibilitar ao investigador um mergulho no campo de estudo "procurando captar o fenômeno a partir das perspectivas contidas nos documentos, contribuindo com a área na qual ele se insere" (KRIPKA; SCHELLER; BONOTTO, 2015, p. 57).

Nesta pesquisa, buscamos identificar os relatórios dos trabaIhos de conclusão de curso (TCC) realizados pelos estudantes do curso de Educação Física da Unochapecó - Licenciatura, no período de 2009 a 2019, caracterizados como pesquisa-ação.

Foram selecionados 23 TCC's, que atenderam aos seguintes critérios: a) ter sido realizado entre o período de janeiro de 2009 e dezembro de 2019; b) estar disponível no repositório digital da biblioteca da Unochapecó ou estar disponível em cópia física no Laboratório Pedagógico de Educação Física (LAPEF); c) constar no título do relatório ou no resumo o termo "pesquisa-ação"; e, d) 
Articulações entre pesquisa e estágio: a pesquisa-ação enquanto estratégia de formação... Jamile Dal-Cin • Neusa Dendena Kleinubing

constar na descrição metodológica do relatório a caraterização de uma pesquisa-ação.

Para a realização desta investigação, foi elaborado um roteiro para leitura e mapeamento dos relatórios, organização dos dados conforme orientações da técnica de análise de conteúdo da Bardin (2009), e após isso, a categorização e análise dos dados.

Dentre os 23 trabalhos foram encontradas pesquisas realizadas no ensino fundamental, ensino médio e em contexto não escolar, os quais foram categorizados em: pesquisas ligadas ao contexto não escolar, percepção dos alunos na escola, pesquisas relacionadas a processos de inclusão e/ou pessoas com deficiência e pesquisas que visam possibilidades de trabalho com conteúdos específicos da Educação Física.

\section{Analisando os TCC's do curso de Educação Física: como a pesquisa-ação tem se apresentado?}

Neste tópico analisaremos as quatro categorias e suas respectivas pesquisas, buscando identificar como a pesquisa-ação tem se apresentado nos trabalhos de conclusão de curso. Entendemos que nós, enquanto formadores, independente do contexto da pesquisa, sendo ela escolar ou não escolar, precisamos criar mecanismos, estratégias para que o estudante encontre formas de pensar sobre (e registrar) o que acontece quando imerso nas suas atividades de docência durante os estágios. Contrapor o que vem estudando e lendo com aquilo que Ihe acontece, quando, no exercício da docência, abre espaço para que novos sentidos/conhecimentos possam ser instaurados na medida em que passam a questionar 0 espaço e as práticas docentes vivenciadas. Dessa forma, Penitente (2012) argumenta que: 
Articulações entre pesquisa e estágio: a pesquisa-ação enquanto estratégia de formação... Jamile Dal-Cin • Neusa Dendena Kleinubing

[...] a pesquisa pode favorecer a emancipação docente, trazendo autonomia aos professores, que deixam de ser meros executores de ideias pensadas por outros para atuarem e contribuírem na construção e sistematização do conhecimento produzido por eles, livres das pressões externas. Por conhecerem as teorias presentes na prática pedagógica, dialogam com o conhecimento teórico produzido fora do contexto escolar. (PENITENTE, 2012, p. 25).

Ao analisarmos os trabalhos selecionados, identificamos que algumas pesquisas focaram em analisar os aspectos de ensino-aprendizagem e pensar em possibilidades/estratégias para o desenvolvimento de um determinado conteúdo. Dentre esses trabaIhos, encontramos pesquisas que tinham como foco discussões sobre inclusão e pessoas com deficiência, os quais realizaram discussões muito parecidas e concluíram ser fundamental a importância de uma conscientização por parte dos professores de Educação Física a respeito da inclusão, bem como buscar estratégias para enfrentar as dificuldades nesse processo. As duas vias de argumentação ressaltam a importância de a inclusão acontecer em todos os níveis: entre os alunos, entre os alunos e a própria prática pedagógica nas aulas, e entre a comunidade escolar e a sociedade.

A categoria que diz respeito ao contexto não escolar, com duas pesquisas encontradas, apesar de abordar situações diferentes, tinha como foco analisar as possibilidades e limitações do método proposto para o ensino-aprendizagem de algum conteúdo específico. Em ambas as categorias, contexto não escolar e pesquisas relacionadas a processos de inclusão e/ou pessoas com deficiência, houve a imersão no contexto selecionado, porém identificamos que a reflexão sobre a prática pedagógica experienciada nessa imersão não foi foco de discussão nesses trabalhos.

Entendemos que a pesquisa-ação, além de pensar estratégias para a resolução dos problemas encontrados nos contextos observados, pode contribuir também para pensar outra problemáti- 
Articulações entre pesquisa e estágio: a pesquisa-ação enquanto estratégia de formação... Jamile Dal-Cin • Neusa Dendena Kleinubing

ca importante relacionada à formação de professores, a qual trata da complexa e ainda mal resolvida relação teoria-prática. Marques (2003, p. 93) argumenta que "não se podem, em nenhum momento, separar teoria e prática, como não se podem elas confundir como se não fossem uma e outra distintas, quer em suas positividades, quer na negação que fazem uma da outra". Ou seja, são dimensões diferentes, porém não podem ser dadas, pensadas de forma separadas, como explica o autor:

\begin{abstract}
Nem a prática é realidade pronta e indeterminada, nem a teoria é sistema autônomo de ideias. Se a prática é ação historicamente determinada, produto e produtora, ao mesmo tempo, da existência social concreta, a teoria não é senão revelação das determinações históricas da prática, delas inseparável, mas delas distinta enquanto negação de realidades postas em separado e acabadas e do esquecimento das determinações da prática. A teoria nega a prática em seus imediatismos, assim como a prática nega a teoria dela desvinculada, exigindo-se ambas em reciprocidade ao negarem-se uma à outra. (MARQUES, 2003, p. 93).
\end{abstract}

A pesquisa na prática docente pode ser considerada como um enfrentamento a essa problemática da relação teoria-prática, pois provoca o movimento dialético da reflexão-ação-reflexão e, conforme afirmam Miranda e Resende (2006), a pesquisa-ação representa uma via privilegiada para a discussão dessa questão no contexto da educação. Corroborando com as autoras, Rufino e Darido (2014) entendem que a pesquisa-ação deveria se fazer mais presente nas investigações específicas da educação - nesta pesquisa pensamos de modo especial na Educação Física escolar - para que seja possível contextualizar suas potencialidades e limitações durante os processos de ensino e aprendizagem, como uma possibilidade de refletir sobre a própria ação provocando uma mudança efetiva na prática pedagógica: "na verdade, a pesquisa-ação deve ser concebida como mais uma possibilidade de pesquisa e reflexão" (RUFINO; DARIDO, 2014, p. 248). 
Articulações entre pesquisa e estágio: a pesquisa-ação enquanto estratégia de formação... Jamile Dal-Cin • Neusa Dendena Kleinubing

Ao analisarmos as pesquisas selecionadas, foram encontradas as que visavam às possibilidades de ensino-aprendizagem de algum conteúdo, em sua maioria relacionados à dança (8 trabalhos). Em todos estes trabalhos, os pesquisadores relataram as reflexões realizadas enquanto estavam inseridos no contexto escolar, abordando, principalmente, a escassez do conteúdo dança nas escolas. Também foi possível identificar nos relatórios que, apesar disso, todas as intervenções alcançaram êxito junto às turmas com as quais trabalharam, concluindo que muitos dos argumentos usados pelos professores para o não trabalho com a dança na escola (KLEINUBING; SARAIVA, 2009) não se sustentam.

Identificamos também reflexões sobre a contribuição que os diferentes conteúdos da Educação Física têm a oferecer para o processo de formação dos sujeitos, sendo estes tão relevantes que não podemos, simplesmente, "deixar a prática acontecer" nas aulas, mas sinalizar sobre a sua importância e sobre a necessidade de trabalhar com a maior diversidade possível de conteúdos, possibilitando ao aluno reconhecer as contribuições de ordem teórica e prática desse campo de conhecimento. Nesse sentido, a pesquisa-ação nos indica um importante caminho que é de que a partir da prática das atividades realizadas no cotidiano, pensadas no planejamento, o professor pode (e deve) produzir conhecimento, pois, como argumentou Marques (2003), as duas se complementam. Não há prática sem teoria e nem teoria sem prática. Essas se retroalimentam para que os conhecimentos possam ir ganhando outros contornos e novos horizontes.

Vemos a importância de investigar a dimensão da pesquisa no contexto da formação de professores de Educação Física, pois conforme afirma Penitente (2012, p. 25), a pesquisa "interfere positivamente na constituição dos saberes docentes e na compreensão de sua própria prática profissional", favorecendo a "tessitura de uma escola em que o conhecimento produzido passa a ser sistematizado, discutido, socializado - uma escola em que as proposições externas se misturam às proposições internas" (PENITENTE, 2012, p. 25). 
Articulações entre pesquisa e estágio: a pesquisa-ação enquanto estratégia de formação... Jamile Dal-Cin • Neusa Dendena Kleinubing

Em todos os TCC's analisados, os relatórios apontaram que os alunos participantes das intervenções adquiriram novos conhecimentos relacionados aos conteúdos trabalhados, mesmo no curto espaço de tempo no qual as intervenções foram realizadas. A exemplo disso, sinalizamos para uma das pesquisas desenvolvidas na escola sobre o conteúdo lutas. Constatou-se que este conteúdo sofre uma exclusão por parte dos professores de Educação Física, por falta de informação ou conhecimento. Diante disso, os pesquisadores sugeriram uma proposta denominada como crítica e emancipatória, identificando transformações positivas no decorrer do processo, a partir de interações, diálogos, reflexões e ações, desmistificando os "tabus" referentes ao conteúdo abordado. Nela, conforme expressam os autores, pode-se perceber que a relação entre teoria e prática foi de extrema importância para a sua realização, possibilitando a inserção de um conteúdo "esquecido" na área da Educação Física.

Outro exemplo que retrata essas questões foi uma pesquisa que tinha como objetivo analisar possibilidades de ensino-aprendizagem do conteúdo ginástica artística nas escolas. Um conteúdo também "esquecido" pelos professores da área, mas que proporciona inúmeros desafios e possibilidades corporais. As pesquisadoras constataram que a vivência desse conteúdo possibilitou ampliar o repertório de movimento dos alunos, com significativa importância no desenvolvimento motor de cada um, bem como a possibilidade de desenvolverem a criatividade, sempre visando à relação teoria e prática para a realização da pesquisa.

Nesse horizonte, Miranda e Resende (2006, p. 511) apontam que a pesquisa-ação é uma concepção que "desde o início, se define por incorporar a ação como sua dimensão constitutiva -, o pesquisador em educação não deixa dúvidas sobre a relevância conferida à prática em seu processo de investigação", pois trata-se de uma pesquisa que "articula a relação entre teoria e prática no processo mesmo de construção do conhecimento, ou seja, a dimensão da prática - que é constitutiva da educação" (MIRANDA; RESENDE, 2006, p. 511). 
Articulações entre pesquisa e estágio: a pesquisa-ação enquanto estratégia de formação... Jamile Dal-Cin • Neusa Dendena Kleinubing

As autoras também relatam que a pesquisa-ação representa um campo privilegiado para as discussões e diálogos acerca da relação entre teoria e prática, pois a própria investigação se transformaria em intervenção social, objeto de estudo e análise, "reflexão e prática, ação e pensamento, pólos antes contrapostos, agora seriam acolhidos em uma modalidade de pesquisa que considera a intervenção social na prática como seu princípio e seu fim último" (MIRANDA; RESENDE, 2006, p. 511).

A pesquisa-ação também coloca em movimento a tensão ainda existente sobre a pesquisa acadêmica, a pesquisa escolar e a pesquisa pedagógica. Nisso, Miranda e Resende (2006) expõem que a pesquisa-ação se concretiza como mais do que uma abordagem metodológica, mas um posicionamento diante de questões fundamentais, como a relação entre teoria e prática, sujeito e objeto, e transformação social. Penitente (2012, p. 22), nesse mesmo horizonte, argumenta que o predomínio de uma concepção clássica de pesquisa impõe um "distanciamento entre a academia e o professor da escola básica, o que restringe a possibilidade de realização de pesquisas por esses professores". Há a necessidade de os professores incorporarem nas suas ações pedagógicas a pesquisa enquanto caminho para superar a dicotomia teoria-prática, bem como a possibilidade de adentar novos conhecimentos com relação às suas práticas e conteúdos.

A partir dos dados analisados, percebemos que a pesquisa-ação tem se apresentado nos trabalhos de conclusão de curso como uma estratégia para apresentação/inserção de um determinado conteúdo e sobre seu processo de ensino-aprendizagem, dando voz ao aluno da educação básica - o que consideramos importante - porém, o "olhar para dentro" do processo de formação é essencial, principalmente nesse momento em que se encontram na condição de formandos, a poucos passos de iniciar a carreira docente.

Na maioria dos trabalhos pesquisados, a pesquisa-ação sustenta a organização da intervenção ocorrida nos estágios curriculares obrigatórios sem considerar o movimento que a pesquisa- 
Articulações entre pesquisa e estágio: a pesquisa-ação enquanto estratégia de formação... Jamile Dal-Cin • Neusa Dendena Kleinubing

-ação oferece para pensar a própria formação docente. A análise e discussão dos dados das pesquisas focam nos resultados da intervenção, considerando o olhar dos estudantes pesquisadores e o conhecimento que foi movimentado/construído durante as aulas. Apenas um trabalho se deteve a analisar a prática pedagógica do pesquisador, refletindo sobre a sua própria ação e inserção no contexto escolhido. Abordaremos sobre essa pesquisa no tópico a seguir, dialogando sobre o estágio e a pesquisa, e a ideia do aluno-protagonista da sua prática pedagógica.

\subsection{Estágio e Pesquisa-ação: porta aberta para o aluno- protagonista}

Como visto anteriormente, a realização do ECO é a porta de entrada do futuro profissional no campo de atuação, e também se constitui como tempo de reflexão e diálogo sobre sua prática pedagógica. Aqui ressaltamos, mais uma vez, a importância da prática da pesquisa imersa nesse momento da formação inicial e o quanto a articulação entre estágio e pesquisa contribuem para o aluno se tornar protagonista nesse processo.

Desde a Lei de Diretrizes e Bases da Educação Brasileira de 1996 e as Diretrizes Curriculares Nacionais para a formação de professores - Resoluções 01 e 02/2002 (BRASIL, 2015) - há a sinalização de que a formação superior tem por finalidade "estimular a criação cultural e o desenvolvimento do espírito científico e do pensamento reflexivo" (BRASIL, 1996), conforme descrito no art. 43, inciso I. Nesse mesmo artigo, a LDB prescreve que a formação de professores deve incentivar o trabalho de pesquisa e investigação científica a fim de que o estudante da licenciatura desenvolva o olhar curioso e crítico sobre o contexto no qual sua atuação se desenvolve.

Nesse sentido, Silva Filho, Lopes e Calvacanti (2011, p. 153) argumentam que a pesquisa pode ocorrer "no e a partir dos está- 
Articulações entre pesquisa e estágio: a pesquisa-ação enquanto estratégia de formação... Jamile Dal-Cin • Neusa Dendena Kleinubing

gios", pois o estudante "necessita dos conhecimentos teóricos e práticos, ou seja, dos conhecimentos científicos para a sua formação" e, neste caso, a pesquisa "é condição sine qua non para o ensino eficiente" (SILVA FILHO; LOPES; CALVACANTI, 2011, p. 153, grifo do autor). Na mesma direção, Assis e Bonifácio (2011) afirmam que a produção científica atua como promotora de conhecimento e que o estudante, ao realizar a pesquisa, desenvolve um olhar crítico e reflexivo. Segundo os autores, a investigação vinculada a uma proposta pedagógica, oportuniza a descoberta de "problemáticas na sua realidade, recursos metodológicos que atendam critérios científicos e acima de tudo que seja um profissional portador de questionamentos e reflexões sobre sua futura atuação profissional" (ASSIS; BONIFÁCIO, 2011, p. 44).

Corroborando os dizeres acima, Kleinubing (2019) traz a ideia do estágio como um "laboratório de criação de práticas pedagógicas" no percurso de quem pretende torna-se professor. Destaca a possibilidade do estágio como um campo do não saber, espaçotempo aberto a experiências novas, aprendendo e produzindo novos saberes e sentidos. Este entendimento pode se articular às possibilidades da pesquisa-ação na formação de professores discutidas anteriormente, pois:

O estágio, como um campo aberto ao acontecimento, mostra-se em seu duplo: como um campo do "ainda não-saber", se radicaliza, pela necessidade de assumir as ações nele realizadas como ações que produzem saberes, nas quais professor-formador, estudante e aluno (da educação básica), articulam-se e participam da produção de sentidos para a Educação Física escolar. Dito de outro modo, se, enquanto campo aberto a acontecimentos, o estágio provoca a ciência de um não-saber, por isso mesmo, convoca o estudante a buscar um novo sentido para suas ações, criando, arranjando, articulando os saberes prévios a fim de constituir outros. (KLEINUBING, 2019, p. 109). 
Articulações entre pesquisa e estágio: a pesquisa-ação enquanto estratégia de formação... Jamile Dal-Cin • Neusa Dendena Kleinubing

Essa ideia amplia significativamente a importância dos estágios, pois todos sabemos que no momento em que "colocamos o pé na escola" os desafios começam a surgir. Não há problema em dar-se conta de que ainda não sabemos o suficiente, ou que ainda temos coisas para aprender. Porém, tornar-se ciente disso deveria provocar o movimento de busca, de produção de novos saberes para suprir a cada passo um pouco da enorme lacuna que existe entre a formação e a efetiva prática pedagógica. Esse deveria ser um movimento natural, pois todos os dias seremos confrontados com novos sujeitos e novas situações que exigirão novas estratégias e tomada de decisão e, consequentemente, reflexões sobre estas. Acreditamos que este deve ser o caminho da prática pedagógica: um incessante fazer-refletir-fazer, caminho que a pesquisa-ação nos possibilita percorrer.

Dos 23 trabalhos selecionados, 15 apresentaram possibilidades de conteúdo no contexto escolar, porém somente um deles relaciona o momento do estágio à pesquisa-ação (DAL-CIN, 2013). Esse trabalho tinha como objetivo analisar as possibilidades de ensino-aprendizagem de uma proposta de intervenção com dança de salão nas aulas de Educação Física no ensino médio durante o estágio supervisionado. A autora dedica um subcapítulo para dialogar sobre a relação entre teoria e prática e o estágio como pesquisa, salientando como a pesquisa durante o estágio a possibilitou visualizar diferentes horizontes durante o processo de intervenção.

A autora relata em seu estudo que a partir da pesquisa-ação no estágio supervisionado ampliou sua visão sobre o contexto escolar, pensando nas aulas como um processo de construção de saberes. Para inserir a dança de salão nas aulas foi preciso elaborar um projeto que atendesse as expectativas dos alunos, as reflexões realizadas em aula e, também, solucionar alguns impasses que foram observados na monitoria, como, por exemplo, a individualidade. Dal-Cin (2013) também ressalta que essas situações foram possíveis de ser contornadas, proporcionando aos alunos um momento de aprendizagem, interação e socialização que só 
Articulações entre pesquisa e estágio: a pesquisa-ação enquanto estratégia de formação... Jamile Dal-Cin • Neusa Dendena Kleinubing

foi possível por estar na posição de pesquisadora, observado o entorno e possibilitando um momento de conhecimento, de trocas. Sobre isso, Pimenta e Lima (2004) afirmam que:

A pesquisa no estágio, como método de formação de futuros professores, se traduz, de um lado, na mobilização de pesquisas que permitam a ampliação e análise dos contextos onde os estágios se realizam; por outro, [...] se traduz na possibilidade de os estagiários desenvolverem postura e habilidades de pesquisador a partir das situações de estágio, elaborando projetos que Ihes permitam ao mesmo tempo compreender e problematizar as situações que observam. (PIMENTA; LIMA, 2004, p. 46).

Nesse horizonte, Kleinubing (2019) salienta que a ideia de articulação entre a pesquisa-ação nos trabalhos de conclusão de curso e os estágios poderia provocar um olhar mais atento para aquilo que acontece, tomando as experiências dos estágios como ponto de reflexão, pois "além de incentivar o estudante a pensar sobre o seu fazer sinaliza para sua condição de partícipe da produção de sentidos no campo da Educação Física, inclusive enquanto futuro professor atuante na educação básica" (KLEINUBING, 2019, p. 126).

Entendemos que nesse processo o estudante se torna protagonista de sua pesquisa, analisando o contexto que está inserido, levando em consideração a cultura, os sujeitos, os diálogos, e não apenas transformando a realidade que se inseriu, mas também expandindo sua visão sobre ser professor, (re)analisando as aulas, problematizando com os sujeitos envolvidos, mantendo um caráter investigativo e avaliativo que provoque mudanças no eu e no outro. É nesse momento que o aluno se posiciona, se coloca num estado de abertura e escuta, desenvolvendo uma atitude investigativa acerca do contexto, procurando na literatura e nos diálogos com outros colegas diferentes soluções para responder às imprevisibilidades encontradas. 
Articulações entre pesquisa e estágio: a pesquisa-ação enquanto estratégia de formação... Jamile Dal-Cin • Neusa Dendena Kleinubing

Ainda analisando o TCC de Dal-Cin (2013), a autora concluiu que a articulação entre o estágio e a pesquisa-ação colocou-a na posição de protagonista e pesquisadora da sua prática pedagógica, trazendo indicativos importantes, como planejar, implementar e avaliar o processo, pois a prática pedagógica não é algo determinado. Nisso cabe ao aluno-protagonista desenvolver ações que causem estranhamento nos sujeitos da pesquisa, instigando-os ao diferente e às diversas possibilidades corporais que a Educação Física escolar pode proporcionar.

Caminhando nessa mesma perspectiva, Higa e Oliveira (2010), dialogando sobre ensino e pesquisa, ressaltam a percepção do aspecto qualitativo na formação dos alunos que se dispõem a fazer pesquisa, principalmente do que diz respeito a buscar alternativas na preparação de atividades didáticas e repensar a sua própria atividade docente. As autoras também revelam que esse momento contribuiu para o aluno tornar-se pesquisador, planejando ações e observando os resultados junto aos alunos. Na mesma direção, Kleinubing (2019) argumenta que os trabalhos orientados pela perspectiva da pesquisa-ação potencializem o entendimento da responsabilidade que temos com a nossa área de atuação, o que implica em estar envolvido cotidianamente no seu saberfazer, reconhecer que os saberes e fazeres relacionados à cultura de movimento se revelam naquilo que vai acontecendo, fugindo do programado, em toda a complexidade do ser.

Dessa forma, percebemos como é importante para os futuros professores essa articulação entre o estágio e a pesquisa-ação, pois essa estratégia solicita ao estudante uma postura de protagonista na sua prática pedagógica. Ser protagonista significa assumir a prática pedagógica como um "jogo" em que prática e teoria se alternam e se retroalimentam, sendo possível neste jogo o surgimento de novos saberes construídos pela dinâmica pedagógica, na troca entre os sujeitos participantes da aula de Educação Física, considerando que os sujeitos e as práticas estão/são na relação com o mundo. 
Articulações entre pesquisa e estágio: a pesquisa-ação enquanto estratégia de formação... Jamile Dal-Cin • Neusa Dendena Kleinubing

\section{Considerações Finais}

A partir da análise dos dados e discussões foi possível identificar que, apesar de termos encontrado um número significativo de TCC's que tinham a pesquisa-ação como delineamento metodológico, poucos refletiram sobre essa proposta de pesquisa em articulação com o processo de formação do professor de Educação Física.

Entendemos que o curso de Educação Física precisa fazer um movimento maior para avançar nesse sentido, a fim de uma articulação entre estágio e pesquisa, já que apenas um TCC, efetivamente, tratou da relação estágio-pesquisa. Conforme dialogamos com os autores que sustentaram as reflexões, visualizamos que a relação estágio-pesquisa, constituída pela pesquisa-ação, se torna passível de novos conhecimentos no momento em que o aluno se coloca na posição de protagonista, identificando limites e possibilidades diante do conteúdo e contexto escolhido para sua pesquisa que, nesse caso, é sinônimo da sua prática pedagógica.

Salientamos a discussão realizada pelo único TCC que tratou efetivamente da relação entre pesquisa-ação e estágio, pesquisa-ação e formação de professores, a qual argumenta que a relação entre teoria e prática e o estágio como pesquisa possibilitou visualizar diferentes horizontes durante o processo de intervenção, bem como a pesquisa-ação no estágio supervisionado ampliou sua visão sobre o contexto escolar, pensando nas aulas como um processo de construção de saberes. Essa reflexão caminha na direção dos argumentos dos muitos autores que defendem essa articulação como forma de qualificar o processo de formação de professores, em especial na formação do professor de Educação Física.

Embora todos os trabalhos selecionados para este estudo discutam os benefícios da pesquisa-ação para pensar a intervenção pedagógica, pouco se discutiu sobre a pesquisa como estratégia de reflexão sobre a própria ação, o que nos leva a pensar que ain- 
Articulações entre pesquisa e estágio: a pesquisa-ação enquanto estratégia de formação... Jamile Dal-Cin • Neusa Dendena Kleinubing

da é necessário avançar nas discussões e nas estratégias de formação docente pela pesquisa.

Diante desse horizonte, apontamos a pesquisa-ação como uma diretriz para a realização dos trabalhos de conclusão de curso, pois entendemos que por meio desse caminho os estudantes têm a experiência da pesquisa articulada à sua prática pedagógica. Nisso, visualizamos que o estágio se abre numa perspectiva de espaçotempo de descobertas, de olhar curioso, estimulando, talvez, o futuro professor da educação básica a produzir conhecimentos a partir de sua prática, um fazer-pensar que todo professor da educação básica deveria tomar para si.

\section{Referências}

ASSIS, R. M.; BONIFÁCIO, N. A. A formação docente na universidade: ensino, pesquisa e extensão. Revista Educação e Fronteiras On-Line, Dourados/MS, v.1, n.3, p.36-50, set./dez. 2011.

BARDIN, L. Análise de Conteúdo. Lisboa, Portugal: Edições 70, 2009.

BRASIL. Resolução CNE/CP 02/2015, de 01 de julho 2015.

\section{Diretrizes}

\section{Curriculares Nacionais para a Formação de Professores da Educação}

Básica, em nível superior, em cursos de licenciatura de graduação plena.

Disponível em: http://portal.mec.gov.br/docman/agosto-2017-pdf/70431-res-cne-cp-002-03072015-pdf/file. Acesso em: 8 ago. 2016.

BRASIL. Lei de diretrizes e bases da educação nacional, $n$. 9.394, de 20.12.1996. Disponível em: http://www.planalto.gov.br/ ccivil_03/Leis/L9394.htm. Acesso em: 8 ago. 2016. 
Articulações entre pesquisa e estágio: a pesquisa-ação enquanto estratégia de formação... Jamile Dal-Cin • Neusa Dendena Kleinubing

DAL-CIN, J. A dança de salão nas aulas de educação física no ensino médio: possibilidades de ensino-aprendizagem. 2013. Trabalho de Conclusão de Curso (Licenciatura em Educação Física) - Universidade Comunitária da Região de Chapecó, Chapecó - SC, 2013.

HIGA, I.; OLIVEIRA, O. B. Desafios na formação docente: a articulação entre ensino e pesquisa. Revista de Educação, Campinas, s. v., n. 28, p. 9-20, jan./jun. 2010. Disponível em: https://seer. sis.puc-campinas.edu.br/seer/index.php/reveducacao/article/ view/66/55. Acesso em: 8 ago. 2016.

KLEINUBING, N. D. $O$ estágio como espaçotempo de experiências na formação em educação física: diálogo com a hermenêutica gadameriana. 2019. Tese (Doutorado em Educação). - Centro de Educação, Universidade Federal de Santa Maria, Santa Maria - RS, 2019.

KLEINUBING, N. D; SARAIVA, M. C. Educação Física escolar e dança: percepções de professores no ensino fundamental. Movimento, Porto Alegre, v. 15, n. 4, p. 193-214, out./dez. 2009. KRIPKA, R. M. L.; SCHELLER, M.; BONOTTO, D. L. Pesquisa documental na pesquisa qualitativa: conceitos e caracterização. Revista de Investigaciones, Bogotá, v. 14, n. 2, p. 55-73, jul./dec. 2015.

MARQUES, M. O. Formação do profissional da educação. ljuí: Unijuí, 2003.

MINAYO, M. C. S. O desafio do conhecimento: pesquisa qualitativa em

saúde, 11 ed. São Paulo: Hucitec, 2008.

MIRANDA, M. G.; RESENDE, A. C. A. Sobre a pesquisa-ação na educação e as

armadilhas do praticismo. Revista Brasileira de Educação, Rio de Janeiro, v. 11 n. 3, p. 511-518set./dez. 2006.

PENITENTE, L. A. A. Professores e pesquisa: da formação ao trabaIho docente, uma tessitura possível. Revista Formação Docente, Belo Horizonte, v. 4, n. 7, p. 19-38, jul./dez. 2012. 
Articulações entre pesquisa e estágio: a pesquisa-ação enquanto estratégia de formação... Jamile Dal-Cin • Neusa Dendena Kleinubing

PIMENTA, S. G.; LIMA, M. S. L. Estágio e Docência. São Paulo, Cortez: 2004.

REZER, R. Educação Física na educação superior: trabalho docente, epistemologia e hermenêutica. Chapecó: Argos, 2014. RUFINO, L. C.; DARIDO, S. C. Pesquisa-ação e educação física escolar: analisando o estado da arte. Revista Pensar a Prática, Goiânia, v. 17, n. 1, p. 242-251, jan./mar. 2014.

SILVA FILHO, A. L.; LOPES, F. M. N.; CAVALCANTE, M. M. D. A dimensão ontológica da trilogia ensino, pesquisa e extensão no estágio supervisionado. In: GOMES, M. de O. (org.). Estágios na formação de professores: possibilidades formativas entre ensino, pesquisa e extensão. São Paulo: Edições Loyola, 2011. p. 135-164

\title{
Publisher
}

\begin{abstract}
Universidade Federal de Goiás. Faculdade de Educação Física e Dança. Publicação no Portal de Periódicos UFG. As ideias expressadas neste artigo são de responsabilidade de seus autores, não representando, necessariamente, a opinião dos editores ou da universidade.
\end{abstract}

